\title{
NEGATIVE LABOR VALUES AND THE JOINT PRODUCTION TECHNIQUE: A DEBATE IN THE MARXIAN TRANSFORMATION PROBLEM
}

\author{
A. Mohtadi*
}

\begin{abstract}
This short paper focuses on a debate between $M$. Morishima and G. Catephores on the one hand, and I. Steedman on the other. It deals with the question of negative labor value in a commodity produced under joint production techniques with no fixed capital and examines the feasibiliy of that question. It demonstrates that Steedman's position, regardless of its internal consistency, is implausible, and that Morishima and Catephores's critique of Steedman is subject to certain limitations. It may be possible to overcome these limitations along the lines suggested, if the latter scheme is to be valid under more general circumstances.
\end{abstract}

Can the labor value of a commodity as it is understood in the Marxian sense be negative? If the answer is in the affirmative, then the validity of the Labor Theory of Value may be seriously questionable, even if highly restrictive conditions were required to render this possible. Recently, Ian Steedman ${ }^{1}$ has attempted to demonstrate that it is in fact possible for a commodity to have negative labor value when it is produced under joint production techniques, along with other commodities. For this, Steedman has relied on the celebrated approach of Piero Sraffa, in which commodity prices and the rate of profit are simultaneously determined in a competitive economy under equilibrium conditions ${ }^{2}$. Steedman's approach has been challenged by Morishima and Catephores (hereafter referred to as $\mathrm{M}$. and $\mathrm{C}$.) ${ }^{3}$, thus opening the

*I wish to thank the editors of RRPE and particularly Richard England for their valuable comments, and Thomas Weisskopf for his helpful suggestions and encouragement. way for a series of debates between the two sides. Following a brief presentation of the basic elements of these debates, a methodological problem inherent in Steedman's scheme will be demonstrated. M. and C.'s alternative formulation of the problem will be examined and suggestions, aimed at generalizing the scope of this formulation, will be offered.

In Marxian value theory the two closely related problems of (1), transforming the labor value of commodities produced under the capitalist mode of production into their prices of production and (2), transforming the rate of workers' exploitation into the rate of profit, are in fact two aspects of a larger problem, known as the Marxian transformation problem ${ }^{4}$. This problem, in its original form emerging from the analysis of Marx, had to fulfill two constraints: (1) that aggregate prices be equal to aggregate values and (2), that the profit rate be identical in both the value and the price schemes. However, in carrying out the task of transformation, Marx did not transform the values associated with the factors of production into their prices of production ${ }^{5}$. This shortcoming, which was later corrected by Bortkiewicz ${ }^{6}$, still left a consistent transformation unattainable under the above two criteria, unless special conditions could be satisfied ${ }^{7}$. However, if the second constraint (i.e., the invariance of the profit rate under the transformation) is dropped then the transformation problem must include not only the transformation of values into prices but also of the profit rate as measured in the value scheme $(\mathrm{S} / \mathrm{C}+\mathrm{V})$ into the profit rate as 
measured in the price scheme $(r)$. The transformation problem as posed at the beginning of this paragraph is a somewhat altered variant of this revised form, in which the invariance of the profit rate is no longer assumed ${ }^{8}$.

Recently, Marxian economists equipped with modern mathematical techniques have shifted attention to a related (but not identical) question of whether any correspondence exists between magnitudes in the value scheme and their counterparts in the price scheme'. Since the existence of such a correspondence is a necessary condition for establishing any transformation, it follows that without a correspondence the very inquiry into the nature of a value-price transformation would be irrelevant. In this context, by demonstrating the existence of a correspondence, Steedman's contribution plays an important, though controversial, role.

In the case of a competitive economy with simple (i.e., not joint) production techniques, and no fixed capital, Morishima and Seton ${ }^{10}$ have shown that the correspondence can indeed be verified, i.e., that the rate of profit in the price scheme is positive if, and only if, the rate of profit is positive. This establishes the necessary conditions for the existence of a transformation operation from the value to the price scheme.

In the case of a joint production technique, however, the story is quite different and this is where the controversies arise. Here it is possible, according to Steedman, to start with negative labor value (and consequently negative surplus value, $S$, as will be demonstrated below) and obtain positive profit rates ${ }^{11}$. Given that the value of labor power, V, is positive, this argument would imply that positive profit rates can in fact be associated with a negative rate of exploitation $\mathrm{S} / \mathrm{V}$, under the condition of joint production techniques. Such an apparent paradox would then imply that the Labor Theory of Value is invalid and would have to be disregarded.

To construct his argument, Steedman assumes two production processes in the context of an input-output model with fixed coefficients. These two processes are as follows:

\begin{tabular}{|c|c|c|c|c|c|c|c|c|}
\hline & $\begin{array}{c}\text { Commodity } \\
1\end{array}$ & & $\begin{array}{c}\text { Commodity } \\
2\end{array}$ & & $\begin{array}{l}\text { Labor } \\
\text { Hour }\end{array}$ & & $\begin{array}{c}\text { Commodity } \\
1\end{array}$ & $\begin{array}{c}\text { Commodity } \\
2\end{array}$ \\
\hline Process 1: & 5 units & + & 0 units & + & 1 unit & - & 6 units & 1 unit \\
\hline Process 2: & 0 units & + & 10 units & + & 1 unit & - & 3 units & 12 units \\
\hline
\end{tabular}

Defining $\left(L^{1}, L^{2}\right)$ to be the vector of labor values in the sense understood by Steedman, ${ }^{12}$ the following two equations result from the above process:

$$
\begin{gathered}
5 L^{1}+0 L^{2}+1=6 L^{1}+1 L^{2} \\
0 L^{1}+10 L^{2}+1=3 L^{1}+12 L .^{2}
\end{gathered}
$$

This system has the solution $\mathrm{L}^{1}=-1$ and $\mathrm{L}^{2}=2$.

To calculate the surplus value, the workers' consumption bundle must be known. Here, for the sake of compatibility between Steedman's and M. and C.'s schemes, the magnitudes used by $M$. and $C$. in their presentation of Steedman's argument will be assumed. ${ }^{13}$ In accordance with this, each worker is assumed to work for 12 hours each work day, receiving 6 units of good 1 and 10 units of good 2 for his subsistence ${ }^{14}$. Since the work done is measured in the units of labor-hours, this subsistence wage for each labor-hour is $(1 / 2,5 / 6)$. The resulting value of labor power per hour will be:

$$
V=1 / 2 L^{1}+5 / 8 L^{2}=1 / 2(-)+5 / 8(2)=7 / 6 \text {. }
$$

On the other hand, the value of total output is found from the right-hand side of system (1), while the value of constant capital is obtained from the sum of the first two terms in each of the equations in system (1). The results are:

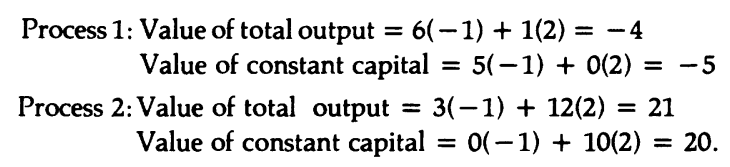

Since $S=$ Value of total output $-C-V$, it follows that $S=$ $-1 / 6$, for either process. The rate of exploitation, $S / V$, is: $\mathrm{S} / \mathrm{V}=(-1 / 6) /(7 / 6)=-1 / 7$, which is identical for both processes.

Now, the same production technique in price scheme can be expressed as:

$$
\begin{aligned}
& \left(5 p^{1}+0 p^{2}+1 / 2 p^{1}+5 / 6 p^{2}\right)(1+r)=6 p^{1}+p^{2} \\
& \left(0 p^{1}+10 p^{2}+1 / 2 p^{1}+5 / 6 p^{2}\right)(1+r)=3 p^{1}+p^{2} .
\end{aligned}
$$

Taking commodity 1 as the numeraire commodity ( $\mathrm{p}^{2}=$ 1) yields the following results:

$$
\mathrm{p}^{1}=0.161 \quad \mathrm{r}=14.38 \% \text {. }
$$

It can be seen from this derivation that a positive rate of profit $(r=14.38 \%)$, is associated with a negative rate of exploitation $(S / V=-1 / 7)$, the latter resulting from the fact that the labor value of commodity 1 is negative, as can be readily verified from the above numerical calculation.

Before turning to M. and C.'s critique of the above derivation it is useful to reflect briefly upon these results. Here, connected with the peculiar association between negative rate of exploitation and positive rate of profit is the fact that the labor value of commodity 1 is negative while its price is positive. A closer scrutiny, however, reveals that both of these peculiarities are related to the fact that process 1 involves a negative amount of total value in the aggregate output of commodities 1 and 2 . To see this, we can substitute values of $\mathrm{L}^{1}=-1$ and $\mathrm{L}^{2}=2$ into equation 1 . This results in -4 units of labor value in the composite output produced in process 1 , which is clearly an unrealistic result. Under the scheme proposed by $M$. and C., however process 1 will not be employed at all and with that the peculiarity associated with the negative value of commodity 1 will be eliminated.

Specifically, M. and C.'s critique ${ }^{15}$ focuses on the plausibility of the concept of negative value by demonstrating that Steedman's values of $L^{1}=-1$ and $L^{2}$ 
$=2$ are not the labor values of commodities 1 and 2, respectively. Instead, according to $M$. and C., they are indices which represent the net change in total labor hours necessary to increase the composite output by one unit. In other words, they correspond not to the absolute magnitude of the value of a commodity, but to the direction of variation of this value as the output is increased by an increment of one unit. M. and C. call this the "employment multiplier" of commodities 1 and 2 respectively.

To find the actual labor value of the composite commodity, M. and C. choose the optimum linear combination of the available production techniques consistent with a minimum of labor hours employed. Under these circumstances, the equations representing the production techniques are no longer constrained to equalities, but are generalized to inequalities, in order to allow for the necessary flexibility to carry out the minimization procedure.

To illustrate this method, and to compare the results with those of Steedman's, first the magnitudes of the multiples of each technique under Steedman's results will be calculated. Thus, using Steedman's figures for the net output vector of $(8,7)$ units, and assuming, along with him, that an appropriate multiple of each technique or process can yield precisely this quantity of output, the system of equations (1) can be expressed in the following matrix form:

$$
\left(\begin{array}{cc}
6 & 3 \\
1 & 12
\end{array}\right)\left(\begin{array}{l}
x^{1} \\
x^{2}
\end{array}\right)-\left(\begin{array}{cc}
5 & 0 \\
0 & 10
\end{array}\right)\left(\begin{array}{l}
x^{1} \\
x^{2}
\end{array}\right)=\left(\begin{array}{l}
8 \\
7
\end{array}\right)
$$

Where, $x^{1}$ and $x^{2}$ are the appropriate multiple of each production technique, with the first matrix corresponding to gross output and the second matrix corresponding to net inputs. The results are:

$$
x^{1}=5, \quad x^{2}=1 .
$$

Under M. and C.'s scheme, the equality in system $(3)$ is replaced by the inequality, $(>)$. The next step involves a linear programming procedure in which $x^{1}$ and $x^{2}$ are calculated such that the total employment, $E$, is minimized under this inequality constraint. Since each technique uses only one hour of labor (See eq. 1), the value of total employment, $E$, is simply:

$$
E=x^{1}+x .^{2}
$$

The resulting magnitudes of $x^{1}$ and $x^{2}$ are: ${ }^{16}$

$$
x^{1}=0, \quad x^{2}=3.5 \text {. }
$$

Clearly, $x^{1}=0$ implies that process 1 will not be utilized at all. This particular result plays a key role in challenging Steedman's results, as we saw earlier.

In the context of the present analysis the above procedure must be able to answer the following questions: (a), How can we calculate the labor value of a single commodity under M. and C.'s scheme? and (b), If the resulting magnitudes differ from Steedman's magnitudes of $L^{1}=$ -1 , and $\mathrm{L}^{2}=2$, what is the economic interpretation of the latter values and how can the difference be accounted for?

To answer the first question, that is to obtain the labor value of a single commodity from the available information on total minimum employment necessary to produce the composite commodity, $\mathrm{M}$. and $\mathrm{C}$. utilize the concept of value as the minimum amount of labor necessary for production, as referred to in Marx's work, The Poverty of Philosophy ${ }^{17}$. This concept has particular relevance in the context of joint production techniques where, according to $M$. and $C$., "the available processes need not be all used, in order to produce a commodity or even all kinds of commodities"18. If we are to accept M. and C.'s identification of value with minimum employment necessary for the production of the composite commodity, then a simple procedure would lead us to the value of a single commodity. We would find the labor value embedded in a single commodity by finding the minimum employment necessary for the production of one unit of the composite commodity such that the latter contains also one unit of the desired commodity and no other commodities.

Using this ingenious scheme, the value of commodity 1 (in our example) could be obtained in the following way: Find $x^{1}$ and $x^{2}$ such that total employment $E=x^{1}+x^{2}$ for the production of $(1,0)$ units of the composite commodity is minimized. The procedure here is identical to the one used earlier. The relevant inequality constraint in this case is:

$$
\left(\begin{array}{cc}
6 & 3 \\
1 & 12
\end{array}\right)\left(\begin{array}{l}
x^{1} \\
x^{2}
\end{array}\right)-\left(\begin{array}{cc}
5 & 0 \\
0 & 10
\end{array}\right)\left(\begin{array}{l}
x^{1} \\
x^{2}
\end{array}\right) \geq\left(\begin{array}{l}
1 \\
0
\end{array}\right)
$$

The results of this minimization procedure are:

$$
x^{1}=0, x^{2}=1 / 3 .
$$

The total employment corresponding to these values of $x^{1}$ and $x^{2}$ is the minimum employment:

$$
E=0+1 / 3=1 / 3 \text {. }
$$

One can now substitute the vector, $x=(0,1 / 3)$, into the left-hand side of the above inequality to obtain the maximum possible output that can be produced under this technique. The result is the net output vector of $(1,1 / 3)$, which is clearly larger than the desired vector $(1,0)$. (Recall that this was also the case earlier (See footnote 16).) The implication of this observation is that the magnitude of $\mathrm{E}$, which can be considered the "actual" labor value of commodity 1 (i.e., the value of commodity 1 as it is contained in the composite commodity), is larger than $\mathrm{L}^{1}$, which is the "theoretic" labor value of commodity 1 (i.e., the value of commodity 1 , if it could be produced alone). This results from the fact that it is not possible to produce 1 unit of commodity 1 without also producing some amount of commodity 2 (in this example $1 / 3$ units of the latter). It is important to note that, regardless of this 
distinction, both the actual and the theoretic labor values of commodity 1 are positive and bear no resemblance to Steedman's value of $L^{1}=-1$. Furthermore, both composite commodities $(1,0)$ and $(1,1 / 3)$ contain the same quantity of actual labor values, leading to the observation that value is not a linearly additive quantity. ${ }^{19}$ Needless to say, an identical procedure would yield the value of commodity 2 .

Having arrived at results different from Steedman's, the second question assumes relevance here: What do Steedman's results actually signify? In answering this question we note that Steedman's values of -1 and 2 do in fact coincide with $\mathrm{M}$. and C.'s notion of an employment multiplier. In particular, the value of -1 is equivalent to a decrease in employment $\mathrm{E}$, by one unit, when the total composite output increases from $(8,7)$ to $(9,7)$, under Steedman's own equality constraints. On the other hand, under M. and C.'s approach no increase in total employment was necessary to increase the output from $(8,7)$ to $(9,7)$ - see footnote 16 -implying that the employment multiplier under this scheme is zero. ${ }^{20} \mathrm{We}$ can say, therefore, that while Steedman's results do indeed satisfy $M$. and C.'s definition of the employment multiplier, their numerical values are different from M. and C.'s; the difference results from the different structures of the two models.

\section{Further Analysis of the Debate}

It can be seen that the above debate is carried on in two different dimensions: In one dimension, Steedman's method is questioned by $M$. and $C$. not because of any internal inconsistencies, but because it leads, on the one hand, to a negative labor value and rate of exploitation and on the other hand to a positive rate of profit. In a second dimension, $M$. and $C$. propose their own scheme aimed at obtaining results which are compatible with the Marxian notion of value, and which lead to plausible correspondence between values and prices. In what follows, each of these two dimensions of the debate will be examined.

(a) To examine the first dimension of the debate, we ask the following question: Is there a sense in which negative labor values can be implied from a general understanding of the notion of value as it was originally formulated by Marx? To answer this question we note that labor value, as understood by Marx, arose from the fact that positive expenditure of work and energy was carried on in the process of production. Thus, ". . . the value of a commodity represents human labor in the abstract, the expenditure of human labor in general... It is the expenditure of simple labor power, i.e., of the labor power which, on the average, apart from any special development, exists in the organism of every ordinary individual." ${ }^{21}$ Moreover, Marx saw the realness of value in the social character of production and exchange. Thus he wrote: "If, however, we bear in mind that the value of commodities has a purely social reality, only in so far as they are expressions or embodiment of one identical social substance., viz., human labor, it follows as a matter of course, that value can only manifest itself in the social relation of commodity to commodity."22 In this context, then, Steedman's magnitude of $\mathrm{L}^{1}=-1$ for commodity 1 , (or, equivalently, the magnitude of -4 for the composite output when produced under process (1)) cannot correspond to a concrete social reality as understood by Marx. ${ }^{23}$

(b) The second dimension of the debate involves $M$. and C.'s alternative formulation replacing Steedman's scheme. This formulation, as noted earlier, is based on the central assumption that under joint production technipurely social reality, only in so far as they are expressions or embodiment of one identical social substance., viz., human labor, it follows as a matter of course, that value ques the process chosen is that which requires minimum labor values. Steedman's position with respect to this assumption is that Marx's more mature works make no specific reference to the labor-minimizing processes discussed by M. and C.. In particular, according to Steedman, the labor value of a commodity was calculated by Marx for only the "socially average conditions of production", which do not always coincide with laborminimizing processes by the capitalists ${ }^{24}$. M. and C. reject this interpretation of Marx by referring to a passage in Marx where both the "least" and the "most" favorable conditions of production are also considered for the calculation of labor value in addition to the average conditions. ${ }^{25}$ Furthermore, according to $M$. and $C$., regardless of this distinction between different "conditions of produc in", which, themselves, are derived from demand conditions, the labor value can always be determined using the laborminimizing techniques by taking the demand and the level of technology as given in each case. Thus, M. and C. write: ${ }^{26}$

"If demand could be basically satisfied by average cost production, then average cost would determine value; if the pressure of demand were high then high cost firms would set the tune; if demand were slack the opposite. But treating the level of demand and the historically developed technological structure of the industry as given, labor would be minimized in the calculation of the amount of socially necessary labor. Thus the idea of labor minimization lingers on in the concept of socially necessary labor."

This aspect of the discourse between Steedman and M. and $C$. involves an attempt by each side to seek certain justifications within Marx's own works, either in support of its own position, or against the position of the other. This endeavor, however, is not entirely in vain. Specifically, a new question has now emerged from $M$. and C.'s argument on the role of demand in the calculation of labor value, as seen from the above quotation. Yet, by treating the demand and technology as given, $M$. and $\mathrm{C}$. do not provide an adequate response for the question they have raised. Specifically, the claim that the 
model ought to take the level of demand and technology as given (i.e., as parameters in the model) is problematic. This is because M. and C.'s calculation of the labor values, as it stands, requires only a knowledge of the state of technology and the subsistence wage bundle (to determine the values, the rate of profit, $r$, and the growth rate). No room is left to take account of the role of demand when calculating the values of commodities. The role of demand, therefore, remains as yet unaccounted for in $\mathrm{M}$. and C.'s model. However, it may be possible to resolve this problem by making the technical coefficients of production function not only of the state of technology but also of the level of demand. Such an approach would, of course, follow M. and C.'s own theme that the level of social efficiency, i.e., the predominance of low, average, or high cost firms, is set by the level of demand. Given that the wage bundle is fixed, it is the knowledge of the technical coefficients of production which would enter into the calculation of the cost function.

In conclusion, the debate between $M$. and $C$. and Steedman, and M. and C.'s reformulation of the method of calculating the labor values of commodities, in particular, appears to be a significant contribution to our understanding of the Labor Theory of Value. However, this reformulation cannot be considered final and must be modified in order to account for the actual factors influencing the processes of production in reality.
A. Mohtadi
Dept. of Economics
University of Michigan
Ann Arbor, Michigan

\section{NOTES}

\section{Steedman (1977)}

${ }^{2} \mathrm{P}$. Straffa (1960). Sraffa's contribution, which takes place within the context of the "Cambridge Controversies," utilizes what amounts to an input-output model of economy in the price scheme leading to the determination of prices and the rate of profit. His discovery of the "borderline industry" in the context of this formulation has been of great relevance to Marxian economics in that while it does correspond to Marx's notion of the "numeraire commodity" in the value scheme it is free from difficulties encountered in finding such a numeraire commodity. Sraffa, by finding a specific mathematical method to obtain the "borderline industry", has in fact demonstrated the plausibility of Marx's "numeraire commodity". Needless to say, the latter is but one of the basic elements of the labor theory of value. For further details and also the equivalence between the two concepts see Howard and King (1975) pp. 150-4.

${ }^{3} \mathrm{M}$. Morishima and G. Catephores (1978).

${ }^{4}$ See, for example, Morishima and Catephores (ibid) p.47.

${ }^{5}$ Marx had been well aware of this problem, as can be seen in volume III of Capital (1967 p.160), but he was unable to modify his analysis at the time.

'Bortkiewicz (1907).

${ }^{T}$ These conditions are (a), that the organic composition of capital in Marx's department III (the luxury good production) be equal to the social average and (b), that the commodity produced in this department be used as the numeraire commodity. For further details and the explanation of these conditions see Howard and King (1975) pp. 147-8.

${ }^{8}$ In this altered version $\mathrm{S} / \mathrm{V}$ is substituted for $\mathrm{S} /(\mathrm{C}+\mathrm{V})$. This modification, however, does not have any bearing upon the arguments to be made in this analysis.

${ }^{9}$ By correspondence we mean the existence of necessary conditions which would guarantee that for a given magnitude in the value scheme, one can find a corresponding value in the price scheme. A transformation, on the other hand, implies the existence of an actual path (or function) which renders possible the mapping from one scheme to the other.

${ }^{10}$ Morishima and Seton (1961).

"Steedman (ibid) pp. 150-161.
${ }^{12}$ Steedman's interpretation of labor values will be discussed below. ${ }^{13}$ See Morishima and Catephores (ibid) p.31.

${ }^{14}$ These magnitudes are somewhat different from those used by Steedman in his book, Marx after Sraffa (1977 p. 154). They are, however, identical to Steedman's magnitudes in an earlier paper (1975 pp. 114-123), where he arrives at the same results as in his book.

${ }^{15}$ Morishima and Catephores (ibid) pp. 29-38; 53-58.

${ }^{16}$ Note that if the net output vector $(8,7)$ is now replaced by a new output vector, $(9,7)$, the same values for $x^{1}$ and $x^{2}$ will result. This, of course, is a consequence of the programming technique employed.

${ }^{17}$ Morishima and Catephores (ibid) p.36.

${ }^{19} \mathrm{M}$. and $\mathrm{C}$. demonstrate this through the use of somewhat more elaborate mathematics in place of the numerical example that has been used here.

${ }^{20}$ Similarly, Steedman's value of $\mathrm{L}^{2}=2$ can be obtained from calculating the increase in the total employment that is necessary to in crease the net composite output from $(8,7)$ to $(8,8)$. Under M. and C.'s scheme the corresponding employment multiplier for the same output change is .5 .

${ }^{21}$ Marx (1967) p.44.

${ }^{22}$ Marx (ibid) p.47.

${ }^{23}$ This argument is not meant to deny the generally recognized fact that a certain epistemological gap has existed between the Labor Theory of Value and the historical materialist explanations of the modern capitalist states by Marxist scholars. Yet, to bridge this epistemological gap need not require the rejection of this theory, but rather its integration into the present mode of Marxian analysis. An attempt in this direction is the work of H. Gintis and S. Bowles (1981, pp. 1-26). This provides a crucial re-examination of the concept of labor power for the purpose of reworking it into an analysis of the modern capitalist society and state. The institutional-cultural influences are not merely regarded as superstructural but as factors which influence the determination of the labor power. Hence, far from being rejected, the Labor Theory of Value has been utilized in this analysis as a tool in understanding the laws of capitalist development.

${ }^{24}$ Steedman (1976) p.606.

${ }^{25}$ Morishima and Catephores (ibid) pp. 56-57.

${ }^{26}$ Morishima and Catephores (ibid) p. 57. 


\section{REFERENCES}

Bortkiewicz, L. Von, "On the Correction of Marx's Fundamental Theoretical Construction in the Third Volume of 'Capital' " (1907) in E. von Bohm-Bawerk, Karl Marx and the Close of His System, ed. P. Sweezy, Kelley, 1966, pp. 199-221.

Gintis, H. and Bowles, S., "Structure and Practice in the Labor Theory of Value", The Review of Radical Political Economics, 12 (Winter, 1981). Howard, M. and King, J., The Political Economy of Marx, (Longman, 1975).

Marx, K. Capital I and III, (International Publishers Co., 1967).

Morishima, M. and Seton, F., "Aggregation in Leontief Matrices and the
Labor Theory of Value", Econometrica, 29 (April, 1961).

Morishima, M. and Catephores, G., Value Exploitation and Growth: Marx in the Light of Modern Economic Theory, (McGraw-Hill, 1978).

Sraffa, P., Production of Commodities by Means of Commodities: Prelude to a Critique of Economic Theory, (Cambridge University Press, 1960).

Steedman, I., "Positive Profit with Negative Surplus Value", Economic Journal, 85 (March, 1975).

Steedman, I."A Replay", Economic Journal, (September, 1976).

Steedman, I., Marx after Sraffa (NLB, 1977).

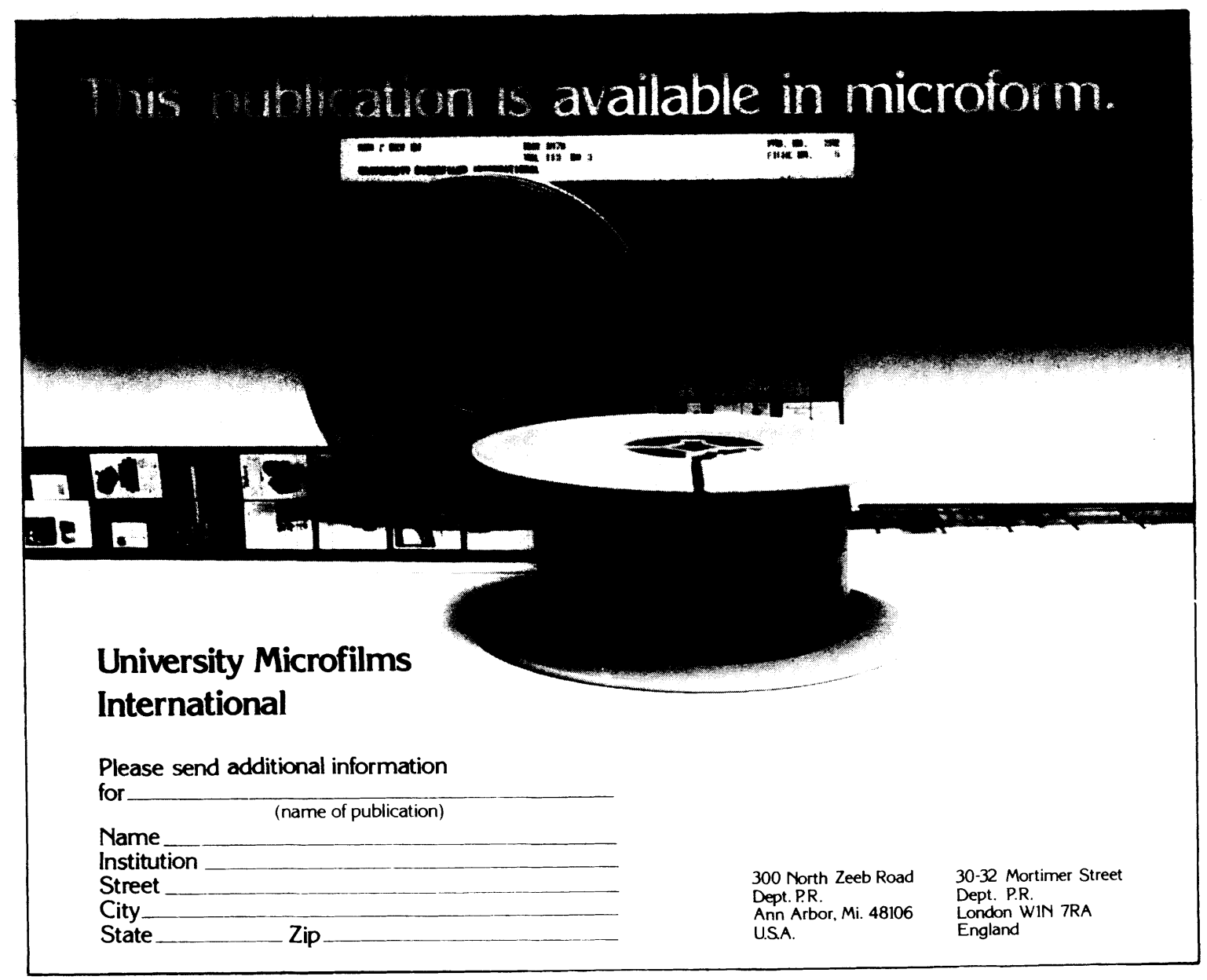

